\title{
ASPECTOS DO IDEÁRIO COOPERATIVISTA E O COOPERATIVISMO NO BRASIL
}

\section{ASPECTS OF THE COOPERATIVIST IDEA AND COOPERATIVISM IN BRAZIL}

\author{
Sergio Fajardo \\ Universidade Estadual do Centro-Oeste, Departamento de Geografia, Guarapuava, PR, Brasil. \\ sergiofajardo@hotmail.com \\ Márcio Mendes Rocha \\ Universidade Estadual de Maringá, Departamento de Geografia, Maringá, PR, Brasil. \\ mmrocha@uem.br
}

\begin{abstract}
Resumo
O presente artigo é parte da pesquisa de Pós-Doutorado desenvolvida entre os anos de 2017 e 2018, cujo objetivo foi apresentar os caminhos tomados pelo cooperativismo praticado no Brasil. Os rumos, muitas vezes, desvirtuaram-se dos ideais originais e os pensamentos dos teóricos precursores do movimento cooperativista dos séculos XVIII e XIX. Nesse contexto, as origens sindical e trabalhista foram esquecidas por muitos defensores do cooperativismo atual. Paralelamente a isso, correntes alternativas, alicerçadas, por exemplo, na Economia Solidária, ganharam espaço no país.
\end{abstract}

Palavras-chave: Movimento Cooperativo. Cooperativismo. Solidariedade. Socialistas Utópicos. Capitalismo.

\begin{abstract}
This article is part of a Postdoctoral research developed between 2017 and 2018. The objective was to present the paths taken by cooperativism practiced in Brazil. The directions were often distorted from the original ideals and thoughts of the precursors of the 18th and 19th century cooperative movement. Furthermore, union and labor origins were forgotten by many defenders of current cooperativism. On the other hand, at the same time, alternative currents, based, for example, on the Solidarity Economy, gained ground in the country.
\end{abstract}

Keywords: Cooperative Movement. Cooperativism. Solidarity. Utopian Socialists. Capitalism. 


\section{Introdução}

O sistema OCB (Organização das Cooperativas Brasileiras) posiciona-se como "oficial" no Brasil, devido ao respaldo jurídico-institucional que possui como representante do cooperativismo brasileiro. Porém, é notável a difusão do cooperativismo considerado alternativo, sendo originado a partir de movimentos sociais e organizações não-governamentais da sociedade civil. Esses movimentos contribuíram para a construção de uma vertente alternativa denominada por vezes como cooperativismo popular ou solidário.

A vertente alternativa de cooperativismo tem como principal influência no Brasil o movimento/proposta de Economia Solidária. Dessa forma, quando confrontadas as propostas do sistema oficial àquelas chamadas solidárias, percebem-se diferenças consideráveis de concepção, mas em sua origem o cooperativismo traz consigo noções e princípios atualmente muito mais próximos às práticas solidárias que ao que se observa em boa parte do chamado cooperativismo oficial, por vezes denominado "empresarial".

Assim, a tese aqui apresentada é de que o sistema OCB apresenta contradições na sua evolução, as quais acentuaram a distância para a essência do cooperativismo original, presente nos precursores, os chamados socialistas utópicos, bem como nos pioneiros de Rochdale. Por esse aspecto, a concepção solidária significaria um resgate dos princípios que estariam perdendo o sentido na prática hegemônica.

\section{Sobre o uso do conceito de cooperativismo}

O conceito de cooperativismo, já bastante abordado, encontra definições diversas (ROCHA, 1999). Historicamente, apresenta-se como doutrina e movimento, também materializou-se como um modelo de gestão. Os chamados Rochdaleanos se fundavam no princípio da equidade, prevendo um sistema justo na distribuição de resultados econômicos do grupo (CRUZIO, 1994).

A cooperativa possui o chamado 'princípio da dupla qualidade", uma vez que o associado é ao mesmo tempo sócio e usuário da organização (MENEZES, 2001). Essa característica de entidade associativa e empresa remonta o conceito de associações de caráter econômico que já existiam há séculos, muitas vezes associados, como observado, ao termo cooperação e ao verbo cooperar. 
Luz Filho (1946) afirma que o cooperativismo tem raízes em expressões e experiências de sociedades antigas, como entre os povos egípcios, babilônicos, gregos, romanos e incas, sendo uma prática até mesmo no período medieval europeu. Entre os exemplos citados pelo autor, muitos poderiam ser identificados como sociedades econômicas e associações, outros que envolviam atividade agrícola se apresentariam com um "caráter cooperativo".

A construção do cooperativismo emerge de um movimento de resistência a um contexto social e trabalhista marcado pela injustiça e desigualdade, pois, no decorrer dos tempos, houve a burocratização e adequação das práticas cooperativistas à ordem moral capitalista (BARBOSA, 2004). Inseridas, inicialmente, como organizações coletivistas de trabalho em um contexto hostil, visavam a emancipação dos trabalhadores diante da exploração capitalista (PONTES, 2007).

O cooperativismo exige que se esvazie o sentido da competição e que seja realçado o sentido da ajuda mútua (ROSSI, 2011). Sobre isso, Namorado (2007) propõe as seguintes características que definiriam uma cooperativa:

- É uma síntese de associação e de empresa;

- Baseia-se na cooperação e na entreajuda dos seus membros;

- Assume como determinantes a democracia interna e a participação;

- Não tem fins lucrativos;

- Procura responder a necessidades e aspirações, quer econômicas, quer sociais, quer culturais;

- É autônoma e independente, em face de quaisquer focos de poder que se lhe queiram impor de fora;

- Tem capital e composições variáveis;

- É dotada de personalidade jurídica.

Para alguns autores, dentre eles, Divar Garteizaurrecoa (2010), a obra "A República", de Platão, trazia elementos da filosofia cooperativista como justiça e cooperação mútua. Na Roma antiga, os colégios romanos funcionavam como associações corporativas e organizações entre sapateiros, carpinteiros, serralheiros e na Rússia, havia uma instituição econômica chamada "artel", que se aproximava da cooperativa moderna, por constituir associações de trabalho baseadas na solidariedade entre seus associados (LUZ FILHO, 1946).

Nesse sentido, Cenzi (2012) indica também como ideias precursoras do cooperativismo aquelas presentes nas obras: Utopia (Thomas Morus, 1480-1535), A 
Nova Atlântida (Francis Bacon, 1561-1626) e A viagem de Içaria (Etienne Cabet, 17881856). Para o autor, essas obras mostram um pouco do desejo de organização social com justiça e fraternidade, a partir da eliminação de diferenças econômicas, alcançada de forma comunitária e coletiva. Na Idade Média, a cooperação demonstrava-se eficiente, à medida que as associações de grupos profissionais conseguiam evitar a competição e o desemprego.

Rech (2000), por sua vez, cita os exemplos dos grêmios do Antigo Egito, que reuniam agricultores escravos com o incentivo do Estado, as tiasas, orglonas e sodalistas na Grécia, que eram associações compostas por escravos e cidadãos livres para organização dos enterros.

O autor Luz Filho (1946) traz exemplos de manifestações cooperativas até mesmo na natureza, destacando o "auxílio mútuo" entre os animais, como os insetos. Ele considera como precursores do movimento cooperativo: Plockboy, Bellers, Robert Owen, William King, Charles Fourier, Philippe Buchez, e Louis Blanc. Em nosso entendimento, outros nomes, entre os chamados utópicos, compõem essa lista, incluindo Saint-Simon, mencionado por Zwick (2016), Prodhon lembrado por Opuszka (2007) e Sismondi, indicado por Pinto et al (2009).

\section{O cooperativismo e os socialistas utópicos}

Os chamados "socialistas utópicos" foram pensadores que tinham como objetivo a defesa da necessidade de construção de uma sociedade mais justa e equilibrada. Como solução para os grandes problemas sociais da humanidade, a posição coletivista voltada ao aspecto social era essencial para as transformações necessárias com vistas ao combate da desigualdade. Essas ações partiriam de iniciativas, dentre as quais, a organização comunitária nas suas diversas formas.

Junto a la crisis que acompanha el advenimiento del sistema capitalista, aparecen idealistas que intentan crear um Estado capaz de assegurar a sus ciudadanos la perpetuidad, la paz, já justicia y el orden. Proponen la eliminación de las diferencias económicas por procedimientos de propiedad comunitária y de trabajo colectivo, desarollo bajo la autoayuda y la solidaridad. Para ello, manifiestan la intención de formar um Estado, a comunidade, indepiendiente, regido por reglas propias y dirigentes elegidos ente el Pueblo para conducirle bajos unas normas de poder limitado (MIRANDA, 2017, p. 34). 
Ainda que a palavra "utopia" remeta a um mundo ideal, como a Utopia de Thomas Morus (CHAUÍ, 2008), o surgimento dos pensadores utópicos era uma reação direta às condições reais e materiais da época.

\begin{abstract}
Os princípios do Socialismo Utópico aparecem com as grandes transformações econômicas que estavam acontecendo na Europa, principalmente na Inglaterra e França. Esse período coincide com as mudanças ocorridas nos processos de produção industrial e comercialização que afetaram diretamente as relações de trabalho entre patrão e empregado. (PINTO et al, 2009, p. 64).
\end{abstract}

Em termos gerais, o conjunto de ideias que podem ser enquadradas como Socialismo Utópico tem como fundamento teórico o desejo humano pelo próprio progresso e renovação, a partir de sentimentos altruístas. No entanto, esquece-se do fato de que o ser humano também é movido por interesses materiais e egoístas (HERNANDEZ, 2005).

Desse modo, é justamente essa outra face, cruel, da perversidade humana, a responsável pelo que há de pior na sociedade, a exploração, a opressão, a humilhação e a desgraça provocados pela desigualdade e egoísmo no mundo capitalista. Em contrapartida, "o socialismo é, para os utopistas a expressão da verdade, da razão, da justiça absoluta, e conquistará o mundo pela força imanente da própria virtude" (ENGELS, 2011, p. 65-66).

Esses pensadores surgem na Europa entre os séculos XVIII e XIX e refletem sobre as promessas não cumpridas da modernidade, ao lado dos movimentos românticos que buscavam no idealismo a saída para uma cruel realidade (OPUSZKA, 2009). Seguindo esse viés, Marx (1996) demonstrava como a utopia de Owen começa a ser colocada em prática no início do século XIX:

Quando Robert Owen, logo depois do primeiro decênio deste século, não só defendeu teoricamente a necessidade de uma limitação da jornada de trabalho, mas também introduziu realmente a jornada de 10 horas em sua fábrica em New-Lanark, isso foi ridicularizado como utopia comunista, assim como sua "união de trabalho produtivo com a educação de crianças", como também as empresas cooperativas dos trabalhadores, fundadas por ele. Hoje em dia, a primeira utopia é Lei Fabril, a segunda figura como frase oficial em todas as Factory Acts e a terceira já serve até como manto de cobertura para embustes reacionários (MARX, 1996, p. 412). 
Parte dos precursores do cooperativismo foram identificados como socialistas utópicos, sendo os principais nomes: Owen, Fourier, Saint-Simon e Blanc. Muitos destes, e seus discípulos imaginaram (alguns tentaram organizar) uma sociedade mais justa, igualitária, com espírito comunitário em busca da equidade e do bem comum, assim como a ilha de Utopia:

Nessa sociedade todos possuem tudo em comum e, portanto, todas as ações e todas as decisões, públicas e privadas, banais ou importantes, deixam de ser orientadas pela cobiça de muitos ou a lascívia de uns poucos, mas têm por objetivo a sustentação de uma única regra uniforme de justiça, de igualdade e de solidariedade comunitária (MORE, 2004, p. 144).

Owen tinha em 1835 um projeto de internacionalização do Cooperativismo, mas somente em 1851, em um congresso nacional que reuniu 44 cooperativas, que essa ideia foi concretizada. CENZI, 2012, p. 28). Sobre isso, Ávila (2017) menciona que o próprio Marx rotulou o "socialismo Oweentiano", por exemplo, de socialismo utópico ou romântico, tendo em vista que buscava mais harmonia que luta de classes.

Os socialistas utópicos foram compreendidos como precursores do socialismo científico, conforme aponta Silva (2007):

A definição de socialismo utópico passou a ser difundida com as teorias marxistas que não concebiam a ideia de uma revolução pacífica, pois as bases econômicas e a luta de classes são o motor da História. O manifesto comunista foi um grande difusor desta definição, mostra que os precursores do sistema socialista compreendiam o antagonismo das classes, mas não viam no proletariado nenhum movimento político que lhes fosse próprio. Para Marx e Engels eram utopistas os socialistas cujas ideias precederam o definitivo desenvolvimento industrial, do proletariado e das classes, portanto suas concepções e questionamentos não consideravam estes fatores. Marx deu uma nova compreensão ao socialismo, onde os precursores do movimento tinham idealizado um futuro inspirado nos planos de organização social, baseando-se em condições fantasiosas.4 Tais formulações contribuíram para o surgimento do socialismo científico, que se sobrepôs ao socialismo utópico. (SILVA, 2007, p. 72).

Para os socialistas utópicos, toda ação deve ser coletiva e incluir todos, pessoas jovens ou idosas, sãos ou doentes, enfim ter um caráter comunitário, democrático e 
inclusivo.Essa visão de mundo influenciou diretamente os pensadores que posteriormente seguiram (MIRANDA, 2017).

O ideário do pensamento coletivo fora então colocado à prova por alguns dos precursores ligados ao socialismo utópico. Assim, sob a ação e influência direta de Owen surgiram comunidades nos Estados Unidos (PINTO et. al., 2009), e sob a inspiração de Fourier, por exemplo, surgiram as colônias no Brasil (GUIMARÃES et al, 2015).

\begin{abstract}
Após o fim das guerras napoleônicas, o movimento operário britânico mudou de rumo. Deixou-se influenciar por Robert Owen, que achava as conquistas da revolução industrial um passo enorme para a emancipação da humanidade e propunha aplicá-las em um novo modo de produção, que denominava socialismo. Este tomaria a forma de aldeias cooperativas, em que a produção e o consumo seriam organizados coletivamente e democraticamente. Se Marx e Engels são os pais do socialismo moderno, Owen deveria ser considerado com justiça o avô. (SINGER, 1998, p. 7).
\end{abstract}

A classe operária foi responsável pela primeira reação ao avanço do modo de produção capitalista no século XIX, nesse contexto, as cooperativas representavam uma forma de resistência à doutrina liberal e individualista (ROSSI, 2011).

Engels (2011) destaca os três grandes utopistas Saint-Simon, Fourier e Owen, que tinham em comum o fato de não se apresentarem necessariamente como representantes do proletariado, mas como aqueles que pretendiam libertar a humanidade inteira, assim como era o ideal de grandes filósofos franceses do século XVIII. Dessa forma, o cooperativismo constituiu boa parte dessa proposta, já, a prática cooperativista fora discutida por Marx e empreendida por marxistas (MARX et. al., 1976).

Diante disso, é possível perceber que o cooperativismo pensado a partir dos ideais do socialismo utópico possuía a mesma intenção, ao menos no plano teórico de transformação social do mundo.

[...] o cooperativismo surgiu como uma estratégia de enfrentamento dos problemas sociais gerados por uma economia individualista, apoiada na cooperação entre os trabalhadores. O cooperativismo é um movimento econômico e social em que a cooperação baseia-se na participação dos associados, nas atividades econômicas com vistas a atingir o bem comum e promover um reforma social dentro do capitalismo.” (ARCANJO; MARQUES, 2012, p. 2). 
Assim, o movimento que reage à Revolução Industrial é produto de suas contradições. No campo teórico, foram construídas diversas teses e proposições que combatiam as mazelas do capitalismo do momento, a maioria com caráter militante.

A resposta à Revolução Industrial na Inglaterra, França e Alemanha será fornecida pelos teóricos Saint-Simon, Proudhon, Fourier e Marx, que contestarão a nova ordem das coisas num nível global, ou seja, na procura de um modelo de sociedade global que seja a negação daquela que emergiu com a Revolução Industrial (TRAGTENBERG, 2005, p. 76).

No que diz respeito ao cooperativismo propriamente dito, o espectro e a diversidade de pensadores que teorizaram ou que utilizaram da práxis para a análise e crítica da sociedade industrial do século XIX é mais ampla. Por essa razáo, elaboramos o Quadro 1, que sintetiza algumas das contribuições dos precursores do cooperativismo.

Quadro 1: Precursores do cooperativismo e suas contribuições

\begin{tabular}{|c|c|}
\hline PRECURSOR & $\begin{array}{c}\text { CONTRIBUIÇÃO AO } \\
\text { PENSAMENTO/MOVIMENTO/DOUTRINA } \\
\text { COOPERATIVISTA }\end{array}$ \\
\hline Peter C. Plockboy (1620-1700) & $\begin{array}{l}\text { Propõe em texto de } 1659 \text {, a organização das chamadas } \\
\text { "pequenas repúblicas". Estas eram associações de base } \\
\text { comunitária, com dirigentes eleitos anualmente, } \\
\text { constituídas por agricultores, artesãos, marinheiros, } \\
\text { professores de artes e ciências. Estabelecia a supressão } \\
\text { do lucro como causa societária, pois era considerado a } \\
\text { origem dos conflitos e desigualdades (DIVAR } \\
\text { GARTEIZAURRECOA, 2010). Influenciou Owen e } \\
\text { Fourier. }\end{array}$ \\
\hline John Bellers (1654-1725) & $\begin{array}{l}\text { Puritano (Quaker) imaginava colônias cooperativas de } \\
\text { trabalho com } 300 \text { a } 3 \text { mil associados, que suprimiriam as } \\
\text { despesas, os lucros, os intermediários as indústrias } \\
\text { consideradas "inúteis", os honorários de advogados, etc. } \\
\text { (LUZ FILHO, 1946). Sugere a criação de casas } \\
\text { comunais e indústrias associadas (SOUZA, 1990). }\end{array}$ \\
\hline Saint-Simon (1760-1825) & $\begin{array}{l}\text { Defendia a educação como princípio fundamental nas } \\
\text { cooperativas, o que levaria à conscientização do } \\
\text { trabalhador sobre a sua condição de explorado } \\
\text { (OPUSKA, 2007). Defendia uma organização } \\
\text { planificada da produção e exaltava a distribuição } \\
\text { proporcional das obras nas cooperativas (ZWICK, } \\
\text { 2016). }\end{array}$ \\
\hline Wiliam King (1786-1865) & $\begin{array}{l}\text { Médico em Brighton, acreditava que a cooperação } \\
\text { eliminaria os males da sociedade e fundou uma } \\
\text { cooperativa de consumo em } 1826 \text { (AGUIAR; REIS, } \\
\text { 2002). Apoiou a criação de cerca de } 300 \\
\text { associações/cooperativas de consumo, editando entre }\end{array}$ \\
\hline
\end{tabular}




\begin{tabular}{|c|c|}
\hline & $\begin{array}{l}1828 \text { e } 1830 \text { o jornal The Co-operator, que difundia } \\
\text { propaganda do sistema cooperativista (SOUZA, 1990; } \\
\text { LUZ FILHO, 1946; MIRANDA, 2017). Influenciou os } \\
\text { tecelões de Rochdale. }\end{array}$ \\
\hline Charles Fourier (1772-1837) & $\begin{array}{l}\text { Francês, contemporâneo de Owen, escreveu várias obras } \\
\text { que focavam a construção teórica dos falanstérios, } \\
\text { associações de produção e de consumo, com caráter } \\
\text { livre e universal que na prática se constituiriam } \\
\text { verdadeiras cooperativas de produção, abrigando } \\
\text { centenas de famílias em uma comunidade societária } \\
\text { (SOUZA, 1990). Buscava suprimir o traço } \\
\text { individualista da propriedade privada (AGUIAR; REIS, } \\
\text { 2002). Defendia que na vida comunitária a renda fosse } \\
\text { repartida entre capital, talento e trabalho (ROCHA, } \\
\text { 1999). Para ele o capitalismo cresce com a miséria do } \\
\text { operário (TRAGTENBERG, 2005). }\end{array}$ \\
\hline $\begin{array}{l}\text { Jean Charles Leonard } \quad \text { S. } \\
\text { Sismondi }(1773-1842)\end{array}$ & $\begin{array}{l}\text { Economista que se tornou crítico do liberalismo, suas } \\
\text { ideias iam em direção ao combate da acumulação e a } \\
\text { exploração do trabalhador (PINTO et al 2009). Defendia } \\
\text { que o Estado regulasse as condições econômicas para } \\
\text { favorecer pequenos produtores agrários (JARAMILLO, } \\
\text { 2005) }\end{array}$ \\
\hline $\begin{array}{l}\text { Philippe Joseph Benjamin Buchez } \\
(1796-1865)\end{array}$ & $\begin{array}{l}\text { Belga, defendia uma associação cooperativa livre, } \\
\text { pacífica e sem espoliação, reunindo operários de mesma } \\
\text { categoria profissional para produção em comum } \\
\text { (AGUIAR, REIS, 2002). }\end{array}$ \\
\hline Robert Owen (1771-1858) & $\begin{array}{l}\text { Precursor do sindicalismo e do cooperativismo defendia } \\
\text { que os sindicatos poderiam administrar as fábricas } \\
\text { (ROCHA, 1999). Condenava o lucro e desejava a } \\
\text { ligação direta entre produtor e consumidor (LUZ } \\
\text { FILHO, 1946). Fundou colônias baseadas na } \\
\text { propriedade coletiva nos Estados Unidos (PINTO et al, } \\
\text { 2009). }\end{array}$ \\
\hline Louis Blanc (1811-1882) & $\begin{array}{l}\text { Foi precursor das chamadas "oficinas sociais" que } \\
\text { constituíam associações de trabalhadores por ramo de } \\
\text { produção (OPUSKA, 2007). }\end{array}$ \\
\hline $\begin{array}{l}\text { Pierre Joseph Proudhon (1809- } \\
1865)\end{array}$ & $\begin{array}{l}\text { A partir dos princípios de justiça, liberdade e igualdade } \\
\text { social, condenava a propriedade privada e defendia a } \\
\text { concepção mutualista que serviu de inspiração ao } \\
\text { cooperativismo (PINTO et al, 2009). }\end{array}$ \\
\hline Ferdinand Lassalle (1825-1864) & $\begin{array}{l}\text { Idealizador do Estado do Bem-Estar Social, vislumbrava } \\
\text { uma sociedade formada por uma grande cooperativa das } \\
\text { classes trabalhadoras (SANTOS NETO; SANTOS, } \\
\text { 2008). }\end{array}$ \\
\hline Charles Gide (1847-1932) & $\begin{array}{l}\text { Considerado o sistematizador do movimento } \\
\text { internacional do cooperativismo, com bases na França e } \\
\text { na Inglaterra. Aprofundou a ideia de solidarismo, em } \\
\text { que os associados a cooperativas realizariam } \\
\text { coletivamente o que individualmente não conseguiriam. } \\
\text { (PINTO et al 2009). Idealizou uma república } \\
\text { cooperativista e foi um dos fundadores da ACI } \\
\text { (OPUSZKA, 2007). }\end{array}$ \\
\hline
\end{tabular}


Historicamente, o cooperativismo apresenta-se como doutrina e movimento, que também materializou um modelo de gestão. Os chamados Rochdaleanos se fundavam no princípio da equidade, prevendo um sistema justo na distribuição de resultados econômicos do grupo (CRUZIO, 1994).

Como afirma Rossi (2011, p. 23), “o cooperativismo é a doutrina que embasa teoricamente a cooperação do ponto de vista econômico, isto é, a união de esforços por meio de associações de fim predominantemente econômicos, as cooperativas". Podemos observar que como "doutrina", o cooperativismo teria sua origem essencialmente econômica, ainda que o escopo dos cooperativistas seja muito mais amplo, buscando alcance social de amplitude mundial.

\section{O cooperativismo e o movimento operário}

A construção do cooperativismo emerge de um movimento de resistência a um contexto social e trabalhista marcado por injustiça e desigualdade, porém, no decorrer dos tempos, seus ideais foram influenciados pela ordem moral capitalista (BARBOSA, 2004). Inicialmente, inseridas como organizações coletivistas de trabalho em um contexto hostil, visavam à emancipação dos trabalhadores diante da exploração capitalista (PONTES, 2007).

Dessa forma, ass cooperativas têm suas raízes na mobilização operária e representaram um movimento de reforma social, surgido a partir da práxis econômica e tem o objetivo de promover modificações no sistema social vigente (MIRANDA, 2017).

Dessa forma, a base original do cooperativismo estava sustentada no proletariado e na organização sindical.

[...] o movimento trabalhista desordenado no final do século XIX luta por uma organização de autodefesa, de protesto e de revolução. Mas, para os trabalhadores pobres, era mais do que um instrumento de luta: era também um modo de vida. O mito liberal supunha que os sindicatos eram compostos de trabalhadores imprestáveis, instigados por agitadores sem consciência, mas, na realidade, imprestáveis eram os menos sindicalizados, enquanto os mais inteligentes e competentes eram os mais firmes em seu apoio ao sindicalismo. (PINTO et al, 2009, p. 63-64). 
Nesse sentido, Cenzi (2012) lembra que a inspiração para a construção de uma doutrina cooperativa estava nos primeiros esforços da classe proletária. Esta buscava a ajuda mútua e a solidariedade, em um momento em que uma parcela de industriais empregadores enriquecia, enquanto a maior parte da população trabalhava demasiadamente recebendo muito pouco e passando fome.

\section{Cooperativismo e resistência ao capitalismo}

Uma das características mais marcantes da economia capitalista está na sua filosofia do lucro e na competição, fato que leva a muitos considerarem impossível uma autogestão, como ocorre na proposta cooperativista (SOTO, 1985).

O Cooperativismo, portanto, nasce enquanto espaço de resistência ao capitalismo ao mesmo tempo em que está umbilicalmente ligado ao mercado, ou seja, o espaço clássico de trocas, onde a lei não é a reprodução da vida de todos, mas, que sobrevivem na competitividade. (OPUSZKA, 2007, P. 409).

As cooperativas são consideradas a partir de sua esfera social e econômica. Sendo a cooperação a raiz do cooperativismo (NAMORADO, 2007), o caráter social das cooperativas estaria justamente em sua gênese, enquanto movimento cooperativista de cunho popular e solidário.

As primeiras ações, voltadas à organização de cooperativas, foram empreendidas por socialistas utópicos de origem humilde e de diferentes profissões que se antecederam às possíveis melhorias que poderiam resultar da experiência cooperativa. Compreender a caminhada da emergência do cooperativismo implica considerar as contribuições desses pioneiros. Embora as suas experiências não tenham perdurado, inspiraram alguns encaminhamentos tomados pelo cooperativismo moderno. Suas ideias estiveram presentes e escritas em romances sociais que idealizaram organizações futuras capazes de abolir os defeitos da sociedade da época. (CALGARO, 2016, p. 12).

Em razão da ligação direta entre o movimento operário e o surgimento do movimento cooperativista no século XIX (RÊGO; MOREIRA, 2013; CALGARO, 2016), no auge da Revolução Industrial, as cooperativas eram vistas quase como uma estratégia de subversão do sistema capitalista. Assim, acreditava-se que a partir da 
lógica em que a expropriação da mais-valia daria lugar a uma organização não capitalista, ainda que integrante à economia de mercado (MORAIS, 2011).

Foi num ambiente bastante fecundo ao surgimento de movimentos sociais (liberalismo econômico no qual a Europa Ocidental se encontrava no século XVIII) que teve origem o movimento cooperativo que, sob efeito das consequências sociais da Revolução Industrial, teve como pressupostos básicos a solidariedade, a equidade, o trabalho em grupo e a liberdade e, como principais idealizadores Owen, Fourier, Buchez, Blanc.” (ROCHA, 1999, p. 3).

Compreendendo que as sociedades cooperativas devam funcionar como um ambiente democrático, onde a participação igualitária nas decisões constitui-se como elemento chave (MAIA, 1985), uma vez que a democracia era bandeira de luta de trabalhadores, que queriam voz e espaço numa sociedade em que a opressão do capital falava mais alto.

Eis que o cooperativismo, em seu berço ainda, já se arvorava como modo de produção alternativo ao capitalismo. O projeto grandioso de Owen equivalia ao que mais tarde se chamou de República Cooperativa, e ela a propôs, não à moda dos utópicos da época aos mecenas para que o patrocinassem, mas ao movimento operário organizado, que ainda estava lutando por seus direitos políticos. Foi um curto, mas inolvidável momento da história da Grã-Bretanha e também do cooperativismo, que vai, deste modo, ainda imaturo, à pia batismal da revolução. (SINGER, 2002, p. 33).

O sentido comunitário, que perpassa a prática coletiva do ideário dos socialistas utópicos, era a ideia, na qual os operários encontravam a possiblidade de empoderamento, para condução de suas próprias vidas.

As cooperativas remontam à primeira metade do século XIX, período marcado, do ponto de vista teórico, pelos socialistas utópicos, SaintSimon (1760-1825), Charles Fourier (1772-1837) e Robert Owen (1771-1858). As experiências que Saint-Simon, Fourier e Owen inspiraram suscitam questões que hoje são "oxigenadas" pela emergência dos empreendimentos autogestionários. Saint-Simon e Fourier têm importância por servir de fonte de inspiração para o movimento cooperativista. Já Owen, além de contribuição no campo teórico, tem também contribuição prática tanto na implantação de seus projetos quanto na organização e luta da classe trabalhadora. (SOUZA, 2008). 
Os socialistas utópicos influenciaram muitas das experiências de movimentos operários e cooperativistas. Diante disso, pode-se afirmar que a essência das cooperativas está no movimento operário, mas que este, evoluiu também a partir da influência dos pensadores, socialistas utópicos, precursores do cooperativismo.

Karl Marx propõe alguns princípios a serem anunciados no primeiro congresso da AIT, os quais referem-se ao cooperativismo, conforme podemos observar em Marx (2002, p. 21-22):

a) "Reconhecemos o movimento cooperativo como uma das forças transformadoras da sociedade actual, baseada no antagonismo das classes. O seu grande mérito é de mostrar na prática que o sistema actual, despótico e empobrecedor, de subordinação do trabalho ao capital, pode ser suplantado pelo sistema republicano da associação de produtores livres e iguais.

b) "Mas o sistema cooperativo restrito às formas ínfimas originadas nos esforços individuais de escravos assalariados é impotente para transformar por si próprio a sociedade capitalista. Para converter a produção social num vasto e harmonioso sistema de trabalho cooperativo são indispensáveis mudanças gerais. Essas mudanças não serão nunca obtidas sem o emprego das forças organizadas da sociedade. Assim, o poder do Estado, arrancados das mãos dos capitalistas e dos proprietários rurais, deve ser manejado pelos próprios produtores.

c) "Com o objectivo de impedir as sociedades cooperativas de degenerar em sociedades ordinárias burguesas (sociedades por ações), qualquer operário empregado deve receber o mesmo salário, seja ou não associado. Como compromisso meramente temporário, transigimos em admitir o lucro mínimo para os sócios.”

(extraído das Resoluções do Primeiro Congresso da A.I.T. , reunido em Genebra em setembro de 1866).

Sobre a doutrina cooperativista no regime socialista, Pinho (1965) coloca que as "pré-cooperativas", como fora mencionado o anteriormente, referem-se às organizações criadas antes dos Pioneiros de Rochdale, idealizadas pelos socialistas utópicos, serviram de referência também aos marxistas, porém com as ressalvas presentes na crítica do próprio Marx.

Assim, o cooperativismo é compreendido sob a ótica marxista como resposta da classe proletária às relações conflituosas predominantes na economia capitalista (NOGUEIRA, 1998). As cooperativas são consideradas a partir das esferas social e econômica. Sendo a cooperação a raiz do cooperativismo (NAMORADO, 2007), o 
caráter social das cooperativas estaria justamente na sua gênese enquanto movimento cooperativista de cunho popular e solidário.

\begin{abstract}
As primeiras ações, voltadas à organização de cooperativas, foram empreendidas por socialistas utópicos de origem humilde e de diferentes profissões que se antecederam às possíveis melhorias que poderiam resultar da experiência cooperativa. Compreender a caminhada da emergência do cooperativismo implica considerar as contribuições desses pioneiros. Embora as suas experiências não tenham perdurado, inspiraram alguns encaminhamentos tomados pelo cooperativismo moderno. Suas ideias estiveram presentes e escritas em romances sociais que idealizaram organizações futuras capazes de abolir os defeitos da sociedade da época. (CALGARO, 2016, p. 12).
\end{abstract}

Para tanto, um ponto a destacar sobre essa questão é a ligação direta entre o movimento operário e o surgimento do movimento cooperativista no século 19 (RÊGO; MOREIRA, 2013; CALGARO, 2016). No auge da Revolução Industrial, as cooperativas eram vistas quase como uma estratégia de subversão do sistema capitalista, a partir da lógica em que a expropriação da mais-valia daria lugar a uma organização não capitalista, ainda que integrante à economia de mercado (MORAIS, 2011).

Foi num ambiente bastante fecundo ao surgimento de movimentos sociais (liberalismo econômico no qual a Europa Ocidental se encontrava no século XVIII) que teve origem o movimento cooperativo que, sob efeito das consequências sociais da Revolução Industrial, teve como pressupostos básicos a solidariedade, a equidade, o trabalho em grupo e a liberdade e, como principais idealizadores Owen, Fourier, Buchez, Blanc”. (ROCHA, 1999, p. 3).

As sociedades cooperativas devem funcionar como um ambiente democrático, onde a participação igualitária nas decisões constitui um elemento chave (MAIA, 1985), pois o sentido comunitário perpassa pela prática coletiva do ideário dos socialistas utópicos. Dessa forma, Souza (2008)

As cooperativas remontam à primeira metade do século XIX, período marcado, do ponto de vista teórico, pelos socialistas utópicos, SaintSimon (1760-1825), Charles Fourier (1772-1837) e Robert Owen (1771-1858). As experiências que Saint-Simon, Fourier e Owen inspiraram suscitam questões que hoje são "oxigenadas" pela emergência dos empreendimentos autogestionários. Saint-Simon e Fourier têm importância por servir de fonte de inspiração para o movimento cooperativista. Já Owen, além de contribuição no campo 
teórico, tem também contribuição prática tanto na implantação de seus projetos quanto na organização e luta da classe trabalhadora. (SOUZA, 2008).

No decorrer do século XX, o movimento cooperativista “oficial”, já organizando e construindo sua estrutura em todo o mundo, começa a distanciar-se de sua origem, cuja base está nos princípios de Rochdale. "Desde o contexto de sua experiência histórica na Inglaterra e nos demais países europeus, os princípios e os valores do cooperativismo vêm sofrendo intencionais lapidações por parte do capitalismo, dada sua reestruturação produtiva." (SANTOS, 2014, p. 425).

Kautsky (1986) já apontava para um crescimento das cooperativas de produção agropecuária em direção ao avanço próprio da produção capitalista. Historicamente, no Brasil, o cooperativismo foi utilizado, sobretudo a partir de 1930, como instrumento de política agrícola (DUARTE; WEHRMANN, 2006).

\section{Os caminhos do ideário cooperativista e o cooperativismo no Brasil}

Antes da fundação da ACI em 1895, as ações dos movimentos cooperativos da Inglaterra, França, Alemanha, Itália e Bélgica resultaram na organização do cooperativismo (NAMORADO, 2013). Inglaterra e França, no entanto, carregaram certa centralidade no processo, conduzindo as cooperativas ao modelo ao qual se propunham. Esse movimento institucionalizado viria a tornar-se o representante exclusivo do movimento cooperativista, oficializado, inclusive, nas legislações posteriores dos países onde as cooperativas se formavam.

Todavia, Webb e Webb (1914) já previam o fenômeno que denominaram de "tese da degeneração das cooperativas", de acordo com Lima (2004), segundo a prerrogativa desses autores, as necessidades empresariais prevaleceriam sobre as chamadas "democracias de produtores" e as cooperativas seriam convertidas em associações capitalistas, visando lucro e contratando assalariados. De fato, se observamos a evolução das grandes cooperativas brasileiras do ramo agropecuário, do século XX ao início do século XXI, percebemos que essa tese se concretizou.

A competição no mercado capitalista materializa a contradição que faz com que as cooperativas tenham que utilizar dos mesmos métodos e estratégias para concorrência no mercado. Luxemburgo (1976) ressalta que essa é uma característica, 
sobretudo, "própria das cooperativas de produção. Por causa dessa contradição, morre a cooperativa de produção, uma vez que se torna ou uma empresa capitalista ou, se os interesses dos operários forem os mais fortes, se dissolve." (LUXEMBURGO, 1976, p. $32)$.

Lima (2004) sintetiza, dessa forma, a crítica dos pensadores Marx e Luxemburgo:

Ora visto como alternativa ao capitalismo, ora como possibilidade dentro do capitalismo, o cooperativismo marcou a esquerda da época. Marx (1977) destacou o avanço do cooperativismo no combate ao capitalismo, mas ressalvava o risco de os trabalhadores se autoexplorarem, dado o fato de serem patrões de si mesmos e dadas as imposições do mercado à produção. À ambiguidade de Marx somouse a crítica de Luxemburg (1979), para quem o fato contraditório de os operários desempenharem o papel de trabalhadores e patrões de si mesmos inviabilizaria as cooperativas de produção, impondo-lhes escolher entre transformarem-se em empresas capitalistas ou dissolverem-se. (LIMA, 2003, p. 47).

Luxemburgo (1976) defende ainda, que a cooperativa só pode existir no seio da economia capitalista, pois suprime a contradição entre modo de produção e modo de troca “[...] subtraindo-se artificialmente, às leis da livre concorrência. Ela só o pode fazer assegurando previamente um mercado, um círculo constante de consumidores [...]” (LUXEMBURGO, 1976, p. 33).

Sendo assim, a construção de uma teoria cooperativista torna-se impraticável, de um lado, por não haver consenso para uma orientação ideal e, por outro lado, a pressão econômica e a própria dinâmica capitalista acaba por ditar os rumos e as estratégias das diversas cooperativas espalhadas pelo planeta.

Enquanto a teoria cooperativista, propriamente dita, está por ser elaborada a doutrina cooperativa vem recebendo contribuições relevantes, a atividade cooperativa multiplica-se em todos os países, através de uma crescente variedade de cooperativas). [...] De modo geral, entretanto, a distância entre a evolução teórico-doutrinária e a prática cooperativista parece cercear relativamente pouco a difusão das cooperativas, já que estas se adaptam às estruturas sócioeconômicas a que pertencem. Mas, correm o risco de um esvaziamento doutrinário, na medida em que o meio se revele hostil aos seus princípios ou às suas normas de funcionamento. E nestes casos, as cooperativas deixam de cumprir plenamente suas finalidades. (PINHO, 1977, p. 69-70). 
Considerada a maior organização não governamental do planeta, a Aliança Cooperativa Internacional (ACI) se colocou como guardiã dos princípios cooperativos, detentora de um status e influência em governos e organismos internacionais jamais vistos (ROCHA, 1999).

Para compreender como o cooperativismo considerado "oficial", representado pela ACI (no Brasil pela OCB), desvirtuou-se é preciso considerar o processo histórico nas ações e estratégias adotadas por muitas cooperativas.

Em 1971, no Brasil, foi aprovada a Lei 576 que atribuiu à OCB a representatividade do sistema cooperativista brasileiro. Dessa data até o ano de 2002, muitas cooperativas que se orientavam nas vertentes sindicais e de economia solidária não reconheciam a representatividade da OCB (PINHO, 2004, p. 4).

Em plena ditadura militar, o Estado encontrava no cooperativismo uma importante estratégia para neutralizar conflitos sociais no campo (AZEREDO, 2016). Ademais, as cooperativas representaram agentes da modernização, que mediaram a instalação no Brasil do modelo produtivo da chamada Revolução Verde (FAJARDO, 2008).

O cooperativismo agrícola auxiliava o Estado a conter as tensões no campo, ao mesmo tempo em que racionalizava e organizava a expansão capitalista no meio rural (CORADINI; FREDERICQ, 2009). Nesse ponto, Gonçalves (1987) afirma que cooperativas passaram a centralizar o capital agrário entre as décadas de 1940 e 1960.Entretanto, elas perderam espaço após a crise cafeeira e início do processo de modernização agropecuária, com a entrada de grandes corporações oligopólicas no país a partir do final das décadas de 1960 e início de 1970.

A partir da aprovação do novo Código Civil em 2002, todas as cooperativas, independente da vertente ou de serem ou não associadas à OCB passam a se orientar por este. O código alterou a forma de tratamento das cooperativas, pois compreendia a cooperativa como uma "sociedade simples", não mais com forma jurídica própria, dispensando capital social para a constituição de cooperativa e deixa de estabelecer um limite mínimo de associados (Lei 5764/1971) (PINHO, 2004, p. 4-5). 


\section{A outra face cooperativista: a vertente solidária}

Desde os primórdios, o cooperativismo carregava consigo um caráter solidário. Assim, os ideais dos socialistas utópicos, precursores do movimento, apresentavam a "cooperação" como alternativa às injustiças sociais provocadas pelo liberalismo econômico, como observados em Owen e Fourier (ROCHA, 1999).

Com a Constituição de 1988, a OCB perde relativamente espaço no controle total do cooperativismo brasileiro, abrindo, assim, o caminho para movimentos alternativos. "Até a Carta de 1988, o cooperativismo brasileiro tinha a interferência estatal na criação, funcionamento e fiscalização das cooperativas" (CENZI, 2012, P. 48). Desse modo, a autogestão prevalece, suprimindo-se o controle estatal.

À margem do sistema OCB, ganha força no Brasil, sobretudo a partir da década de 1990, a vertente solidária. Esta aborda os problemas contemporâneos a partir da chamada Economia Solidária, cujo foco está nas práticas econômicas populares, muitas das vezes informais e de caráter coletivo (BARBOSA, 2004).

Com a ascensão de um governo progressista no Brasil, a partir de 2003, ocorre a tentativa de ampliar a teorização e institucionalizar a Economia Solidária, ainda que sob críticas de muitas linhas marxistas (GERMER, 2007). O cooperativismo, por sua vez, constituiu boa parte dessa proposta.

Ainda que o cooperativismo tenha vínculo histórico com um projeto alternativo ao capitalismo e era crítico a este, o movimento não tinha como bandeira política o socialismo (MONDADORE, 2013), embora, não se pode negar a origem social e coletiva do movimento e da doutrina cooperativista que, inserido no capitalismo, obviamente, jamais poderia constituir-se em oposição a este mercado, ainda que conflitante em alguns pontos da lógica capitalista.

A luta pela organização desse modelo de cooperativa envolveu o esforço de movimentos sociais e de Organizações Não-Governamentais, além de instituições públicas, como as universidades com vistas ao enfrentamento dos problemas sociais que afetavam a população.

As mudanças na legislação foram fundamentais para o reconhecimento do modelo solidário de cooperativa, tendo em vista que a hegemonia do sistema OCB tinha bases legais e força de representatividade. "A vertente cooperativa solidária não era reconhecida pela OCB (Organização das Cooperativas Brasileiras), por considerá-la 
pouco viável, sobretudo do ponto de vista autogestionário cooperativo e econômico" (PINHO, 2004, p. 8).

Outra iniciativa de cooperativismo paralelo ao sistema OCB são as iniciativas do MST, nos assentamentos de Reforma Agrária, com a criação em 1990 do Sistema Cooperativista dos Assentados - SCA (VAZZOLER, 2004). O modelo do MST apresenta também sua proposta alternativa ao sistema tradicional, revelando ainda um pouco do viés "solidário", apesar de não se denominar como tal, quando reforça o caráter de cooperação entre as famílias assentadas.

Ainda dentro do escopo alternativo no qual se insere a vertente solidária estão as "cooperativas populares". Essas iniciativas podem ser também consideradas como solidárias ao valorizar a solidariedade como instrumento de luta e sobrevivência coletiva (CULTI; TENÓRIO; CHAVES, 2001).

Desse modo, o movimento em direção à construção de um modelo econômico alternativo (dentro da economia de mercado), no Brasil, ganha força a partir da redemocratização, com o fim da ditadura militar, em meados doa anos 1980. Nesse período, surgem e se manifestam muitas entidades (associações, ONGs, igrejas etc.) com o intuito de amenizar graves problemas sociais.

Desde os anos 1980, as experiências coletivas de unidades econômicas, denominadas hoje de "economia solidária" já ocorriam na América Latina (BARBOSA, 2004). No Brasil, a crise dos anos 1980 acarretou a organização de iniciativas solidárias, como os casos da Anteag e Unitrabalho, entre outras, além de iniciativas da Igreja Católica, como a Cáritas (PINHO, 2004). Nessa direção, constata-se que a reorganização dos movimentos sociais foi essencial no período posterior à Ditadura Militar brasileira.

\section{Cooperativismo, solidariedade e o pensamento à esquerda}

Embora o cooperativismo em geral tenha vínculo histórico, efetivando-se como um projeto alternativo ao capitalismo, sendo crítico a este regime, o movimento não tinha como bandeira política o socialismo (MONDADORE, 2013).

Nos países socialistas, durante o século XX, muitas cooperativas foram criadas, ainda que com ressalvas à aceitação do modelo Rochdaleano, como aponta Pinho (1965, p. 103): “[...] a aceitação do cooperativismo no meio socialista reflete o 
predomínio atual das ideias marxistas, ou seja, atitude de reserva quanto às possibilidades de reforma total da sociedade através das cooperativas."

Observa-se então, que o cooperativismo nos países socialistas fugia ao modelo rochdaleano, embora os formatos de cooperativas se assemelhassem.

Os Princípios de Rochdale não têm sido a razão da implementação de cooperativas, tanto no socialismo como no capitalismo. No capitalismo, o capital centralizado na cooperativa contribui para o aumento da escala de produção fazendo crescer o trabalho excedente em relação ao trabalho necessário e esse sobretrabalho é apropriado pelo cooperado. Nesse sentido o associado da cooperativa toma feição de empresário capitalista negando as propostas reformistas rochdaleanas. (GONÇALVES, 1987, p. 20).

Lenine (1976) destaca a importância das cooperativas para o regime socialista e distingue as cooperativas na URSS, onde a terra e os meios de produção pertencem ao Estado, das cooperativas capitalistas que funcionam como empresa privada, ainda que coletiva. Mao (1976) também relata a multiplicação de cooperativas agrícolas na China.

Ao questionar o modelo cooperativista proposto por socialistas utópicos como Owen, Lenine (1976) indica que o aspecto idealista e utópico daqueles pensadores estaria ligado ao fato de que eles não vislumbravam a luta de classes.

Os planos dos antigos cooperadores, a começar por Robert Owen, em que medidas são quiméricos? É que se sonhava transformar pacificamente a sociedade moderna pelo socialismo, sem ter em conta questões essenciais como a luta de classes, a conquista do poder político pela classe operária, o derrubamento do domínio da classe dos exploradores. Eis porque temos razão para dizer que esse socialismo 'cooperativo' é algo puramente fantástico, romântico e mesmo vulgar, já que se sonha transformar os inimigos de classe, e a luta de classes numa paz de classes (paz social, como se costuma dizer), pelo simples agrupamento da população em cooperativas. (LENINE, 1976, p. 44).

Sabe-se sobre a origem social e coletiva do movimento e da doutrina cooperativista, que, embora inserida no capitalismo, não poderiam demonstrar-se contrário, ainda que divergindo em alguns pontos da lógica capitalista.

Por outro lado, o pensamento socialista encontrou também no cooperativismo um aliado importante. 
$\mathrm{Y}$ en los comienzos del siglo XX, el cooperativismo aparece como aliado de las alternativas socialistas. Marca el comienzo de tales participaciones el Partido Cooperativo Británico (Cooperative Party) en 1917, organización con sede central en Londres y vigente en la actualidad, que se presenta a las elecciones conjuntamente con el Partido Laborista, defendiendo en su seno la llamada "tercera vía" (entre la economía pública y la capitalista). (GARTEIZAURRECOA, 2010, p. 149).

Conforme apontado anteriormente, a organização desse modelo de cooperativa envolveu grandes esforços de movimentos sociais e de Organizações NãoGovernamentais, e muitas outras entidades e instituições, como forma de enfrentar os graves problemas sociais do período.

A emergência do 'cooperativismo solidário' significa o reconhecimento de outra lógica gestionária na busca de uma nova economia que consiga abranger os micros (microcrédito, microempreendedores, microautogestores, clubes de trocas e outros) e os excluídos (sem-teto, sem-terra, se-conta bancária, sem-garantia patrimonial). Para isso, tenta formas de rearranjo econômico e social com base na cooperação espontânea e na solidariedade. Tentativa que fez surgir uma nova vertente cooperativa solidária, paralela ao cooperativismo tradicional, e embasada na ética, no caráter dos associados e em sua mútua confiança e espírito de solidariedade. (PINHO, 2004, p.7).

Entre as décadas de 1980 e 1990, o desemprego, o início da flexibilização na legislação trabalhista e a expansão da informalidade no trabalho motivaram várias organizações não-governamentais, movimentos sociais e entidades a proporem o associativismo e o cooperativismo popular como alternativa (CANÇADO, 2005).

Todavia, a representatividade exclusiva da ACI/OCB marginalizava muitas cooperativas. As mudanças na legislação foram fundamentais para o reconhecimento do modelo solidário de cooperativa, tendo em vista que a hegemonia do sistema OCB tinha bases legais e força de representatividade.

\section{Considerações finais}

A essência do cooperativismo originário e de sua doutrina seria justamente calcada na crítica às mazelas provocadas pelo liberalismo econômico no século XIX. Porém, em pleno século XXI, dentro do cooperativismo se mantém uma tipologia de 
cooperativa aliada ao pensamento neoliberal da flexibilização trabalhista, que coloca, novamente, os trabalhadores em condições de precariedade.

Concomitantemente à ascensão do neoliberalismo no mundo, o processo de globalização econômica torna-se promotor das políticas deste pensamento. Assim, enquanto forças progressistas avançam na luta pela regulamentação plena da Economia Solidária e por sua fomentação como política de Estado, outros atores fazem o contraponto resistindo às mudanças.

Não se pode negar a importância do cooperativismo e seu papel econômico desde o século XIX até a atualidade, internacionalmente e especificamente no Brasil. No entanto, é preciso filtrar o romantismo presente nos discursos por vezes bucólicos que não devem ser interpretados ingenuamente.

Como pudemos observar na presente pesquisa, durante o século XX, no Brasil, o cooperativismo com base rochedaleana e representante oficial da ACI desenvolveu-se, inicialmente, com bastante dificuldade, reunindo uma diversidade de iniciativas, de ramos variados e atendendo a uma parcela da população que realmente necessitava de um suporte. A organização coletiva vinha ao encontro de uma demanda por oportunidades econômicas de inserção a consumidores, trabalhadores, produtores rurais, etc.

No entanto, com o passar do tempo, o cooperativismo brasileiro, com apoio do Estado e muitas vezes coordenado diretamente por este, caminhou em direção a objetivos, sobretudo, econômicos em detrimento do caráter social, que está na essência do que deveria significar o cooperativismo.

Deste modo, tem-se de um lado, muitas cooperativas se agigantaram tal qual grandes empresas, acumulando capital e patrimônio. Por outro lado, um número significativo de pequenas cooperativas, sem condições de competir no mercado foram desaparecendo ao longo do tempo. O exemplo das cooperativas do ramo agropecuário, talvez o que tem o maior destaque econômico no país, ilustra bem essa condição.

Não obstante, os discursos dos representantes das cooperativas ainda carregam a aura romântica dos primórdios do movimento cooperativo. Dessa forma, selecionamos alguns trechos de matérias publicadas, os quais indicam que os discursos, em certos momentos, contradizem a propalada doutrina cooperativista. 
Não podemos generalizar a diversidade imensa de cooperativas e a complexidade dos vários ramos, que podem ter maior ou menor presença no mercado, giro de capital, patrimônio etc. Porém, analisando a partir do modelo hegemônico, representado oficialmente pela OCB, basicamente, grandes e pequenas cooperativas possuem condições melhores ou piores de atuação, de acordo com a sua dimensão, tal como acontece com as demais empresas.

Ao refletirmos sobre as diferentes posturas dos dois modelos conflitantes identificamos uma dualidade clara. Nota-se que, no caso das organizações solidárias, as cooperativas presentes nesse sistema alternativo aproximam-se muito em seus princípios e ações com muitas das propostas e idealizadas pelos precursores do cooperativismo.

Podemos constatar que, enquanto o cooperativismo considerado oficial evoluiu no Brasil, para a consolidação de uma proposta plenamente alinhada aos propósitos empresariais, o sistema alternativo significou uma espécie de resgate dos ideais originais do cooperativismo.

Consideramos então, plenamente justificável o questionamento da exclusividade por organizações cooperativas alternativas. É fato reconhecido, não apenas pelas entidades e por movimentos sociais ligados à Economia Solidária, mas também pelos próprios representantes do sistema $\mathrm{OCB}$, que há diferenças significativas entre as concepções de cooperativismo de um e de outro lado. Por essa razão, não caberia integrar aquilo que não pode ser aproximado, um paradoxo que não vale a pena insistir.

Além disso, não é aceitável que se use de um discurso que marginalize as cooperativas alternativas, colocando-as como "fora da lei". Há que se ter o bom senso necessário, com o intuito de rever a legislação e se promover a justiça aos inúmeros grupos solidários que lutam por condições de sobrevivência coletiva.

\section{REFERÊNCIAS}

AGUIAR, Cristina Silveira; REIS, Carlos Nelson. As origens do cooperativismo e o contraponto aos males das metamorfoses do trabalho. Sociedade em Debate, Pelotas, v. 8, n. 3, dez. 2002, p. 149-183.

AZEREDO, Raoni Fernandes. Agronegócio cooperativo da Coamo: territorialização, poder e controle. Dissertação (Mestrado em Desenvolvimento Territorial na América Latina e Caribe), São Paulo: Unesp, 2016, $137 f$. 
BARBOSA, Rosangela Nair de Carvalho. O cooperativismo e a questão social no contexto da globalização excludente. In: VIII Congresso Luso-Afro-Brasileiro de Ciências Sociais, Coimbra, 16 a 18 de setembro de 2004. P. 1-21.

CALGARO, Rosane. Empresificação das cooperativas: contradições da trajetória cooperativista contemporânea. In: IV Congresso Brasileiro de Estudos Organizacionais. Porto Alegre, 19 a 21 de outubro de 2016, p. 1-23.

CANÇADO, Airton Cardoso. Gestão social e economia solidária- para além do mimetismo: outra gestão é possível? Revista Economia Solidária. Ponta Delgada (Portugal), n. 10, dez. 2016, p. 20-44.

CENZI, Neri Luiz. Cooperativismo: desde as origens ao projeto de Lei de reforma do sistema cooperativo brasileiro. Curitiba: Juruá, 2012, 171p.

CHAUÍ, Marilena. Notas sobre utopia. Ciência e Cultura, v. 60, n. esp. 1, São Paulo, jul., 2008, P. 7-12.

CORADINI, Odacir L.; FREDERICQ, Antoinette. Agricultura, cooperativas e multinacionais. Rio de Janeiro: CEPS, 2009.

CRUZIO, Helnon de Oliveira. Ideologia e autogestão. Contradição do cooperativismo agropecuário/industrial brasileiro: o caso da inversão decisória. Tese (Doutorado em Administração). São Paulo: FGV/EAESP, 1994, 282p.

CULTI, Maria Nezilda; TENÓRIO, Maria Clara; CHAVES, Dieine Aparecida. Cooperativismo popular: um processo de (Re)Educação. In: $5^{\circ}$ Congreso Nacional de Estudios del Trabajo. Buenos Aires, 1 a 3 de agosto de 2001, p. 2-21.

DIVAR GARTEIZAURRECOA, Javier, Reflexiones: Peter Cornelius Plockboy y la república cooperativa. Revenesco, Madri, n. 102, $2^{\circ}$ quad. 2010, p. 145-153.

DUARTE, Laura Maria Goulart; WEHRMANN, Magda. Histórico do cooperativismo agrícola no Brasil e perspectivas para a agricultura familiar. In: SABOURIN, Eric (org.). Associativismo, cooperativismo e economia solidária. Cadernos do CEAMUnB, Brasília, v. 6, n. 23, jan. 2006, p. 29-62.

ENGELS, Friedrich. Do socialismo utópico ao socialismo científico. São Paulo: Edipro, 2011, 95p.

FAJARDO, Sergio. Territorialidades corporativas no rural paranaense. Guarapuava: Ed. Unicentro, 2008, 414p.

GERMER, Claus. A 'economia solidária': uma crítica marxista. In: GEDIEL, José Antônio Peres (org.). Estudos de direito cooperativo e cidadania. Curitiba: Ed. UFPR, 2007, 244p. 
KAUTSKY, Karl. A Questão Agrária. (Tradução de Otto Erich Walter Maas). São Paulo: Nova Cultural, 1986.

LENINE, V. Sobre a cooperação. In: LUXEMBURGO, Rosa. As cooperativas. In: MARX, K.; LENINE, Vladimir I.; MAO, Tsé-tung; LUXEMBURGO, R. PREOBRAJENSKY, E. Cooperativismo e socialismo. Coimbra: Centelha, 1976, p. $35-48$.

LUXEMBURGO, Rosa. As cooperativas. In: MARX, K.; LENINE, Vladimir I.; MAO, Tsé-tung; LUXEMBURGO, R. PREOBRAJENSKY, E. Cooperativismo e socialismo. Coimbra: Centelha, 1976. P. 31-34.

LIMA, Jacob Carlos. O trabalho autogestionário em cooperativas de produção: o paradigma revisitado. Revista Brasileira de Ciências Sociais, São Paulo, v. 19, n. 56,out. 2004.

LUZ FILHO, Fabio. Teoria e prática das sociedades cooperativas. Rio de Janeiro: Olímpica Editora, 1946, 663p.

MAIA, Isa. Cooperativa e prática democrática. São Paulo: Cortez, 1985, 112p.

MAO, Tse-tung. Sobre o problema da cooperação agrícola. In: LUXEMBURGO, Rosa. As cooperativas. In: MARX, K.; LENINE, Vladimir I.; MAO, Tsé-tung;

LUXEMBURGO, R. PREOBRAJENSKY, E. Cooperativismo e socialismo. Coimbra: Centelha, 1976. P. 61-108.

MARX, Karl. O cooperativismo. In: MARX, K.; LENINE, Vladimir I.; MAO, Tsétung; LUXEMBURGO, R. PREOBRAJENSKY, E. Cooperativismo e socialismo. Coimbra: Centelha, 1976. P. 13-30.

MONDADORE, Ana Paula Carletto. Mondragón é aqui? Cooperativismo e internacionalização. Tese (Doutorado em Ciências Sociais). Campinas: Unicamp, 2013, $156 f$.

MORAIS, Edson Elias de (et al.) Propriedades coletivas, cooperativismo e economia solidária no Brasil. Serviço Social Sociedade, São Paulo, n. 105, p. 67-88, jan./mar. 2011.

NAMORADO, Rui. Cooperativismo: história e horizontes. In: GEDIEL, José Antônio Peres (org.). Estudos de direito cooperativo e cidadania. Curitiba: Ed. UFPR, 2007, 244p.

NOGUEIRA, Alberto Marcos. Cooperativismo de trabalho e cooperativismo no Brasil: uma análise marxiana. Dissertação (Mestrado em Economia), UFRGS, 1998, $114 \mathrm{f}$.

PINHO, Diva B. A doutrina cooperativista nos regimes capitalista e socialista. São Paulo: Pioneira, 1965, 161p. 
PINHO, Diva B. Economia e cooperativismo. São Paulo: Saraiva, 1977.177p.

PINHO, Diva B. O cooperativismo no Brasil: da vertente pioneira à vertente solidária. São Paulo: Saraiva, 2004, 357p.

PONTES, Daniele Regina. Configurações contemporâneas do cooperativismo brasileiro. In: GEDIEL, José Antônio Peres (org.). Estudos de direito cooperativo e cidadania. Curitiba: Ed. UFPR, 2007, p. 89-112.

RÊGO, Eduardo Ernesto do.; MOREIRA, Emilia. Cooperativismo: uma breve discussão teórico-conceitual perpassando pelo socialismo utópico, marxista e anarquista. Revista OKARA: Geografia em debate, João Pessoa, v.7, n.1, p. 63-80, 2013.

ROCHA, Eliza Emília Rezende Bernardo. O cooperativismo agrícola em transição: dilemas e perspectivas. Tese (Doutorado em Economia). Campinas, Unicamp, 1999, $236 p$.

ROSSI, Amélia do C. S. Cooperativismo à luz dos princípios constitucionais ( $3^{\mathrm{a}}$ ed). Curitiba: Juruá, 2011, 182p.

SANTOS, Ana Maria Marques. Da gênese das contradições: a contradição capitaltrabalho e a sociabilidade do cooperativismo popular. Revista Política Pública, São Luís, Número Especial, p. 423-428, julho de 2014.

SINGER, Paul. Introdução à economia solidária. São Paulo: Perseu Abramo, 2002, $127 \mathrm{p}$.

Para além do neoliberalismo: a saga do capitalismo contemporâneo. São Paulo em Perspectiva. São Paulo, v. 12, n. 2, 1998, p. 3-20.

SOUZA, Jean Adriani de. O trabalho associado em Karl Marx: contribuição ao debate acerca do cooperativismo e da transição. Dissertação (Mestrado em Sociologia Política). Florianópolis, Ufsc, 2008, 108f.

VAZZOLER, Márcia Regina. Cooperativismo e assentamentos de reforma agrária: a sobrevivência de cooperativas do MST no contexto capitalista. Tese (Doutorado em Engenharia de Produção), São Carlos, UFSC, 2004, 340f.

WEBB, S.; WEBB, B. Co-operative production and profit sharing. New Statesman, London, v. 2, n. 45, 1914.

Recebido em 15/10/2021.

Aceito para publicação em 06/11/2021. 